\title{
Endoscopic Endonasal Resection of C1-C2 Pannus, a Step-by-Step Surgical and Anatomical Description: 2-Dimensional Operative Video
}

\author{
Mohamed Samy Elhammady ${ }^{1,2}$ Mohammad Al-Bar 3,4 \\ ${ }^{1}$ Neuroscience Institute, Neurological Surgery Department, \\ Cleveland Clinic Abu Dhabi, Abu Dhabi, United Arab Emirates \\ ${ }^{2}$ Cleveland Clinic Lerner College of Medicine, Case Western Reserve \\ University, Ohio, USA \\ 3 Otolaryngology Head and Neck Surgery, King Fahd Hospital \\ ${ }^{4}$ Imam Abdulrahman Bin Faisal University, Al Khobar, Saudi Arabia
}

\author{
Address for correspondence Mohamed S. Elhammady, MD, \\ Neuroscience Institute, Neurological Surgery Department, Cleveland \\ Clinic, Al Maryah Island, PO Box 112412, Abu Dhabi, United Arab \\ Emirates (e-mail: samyelhammady@gmail.com).
}

J Neurol Surg B 2021;82(suppl S1):S6-S7.

\begin{abstract}
Keywords

- craniocervical junction

- expanded endoscopic endonasal approach

- C1-C2 pannus

- craniocervical decompression

Expanded endonasal endoscopic approaches provide access to the entire central skull base and craiocervical junction. The authors present a case of an 81-year-old man who presented with progressive spastic quadriparesis to the point of being wheel-chair bound. Cervical spine computed tomography $(\mathrm{CT})$ and magnetic resonance imaging (MRI) demonstrated multilevel extensive spondylitic changes with a large pannus at the C1-2 junction, severely compressing the spinal cord (-Figs. 1 and 2). Given the significant anterior spinal cord compression and the patient's substantial weakness, the decision was made to perform an endoscopic endonasal anterior cervical decompression and resection of the pannus followed a posterior cervical fusion. The patient recovered well following surgery with significant improvement of motor function. The preoperative assessment, the step-by-step surgical technique, and the technical nuances are demonstrated and discussed.

The link to the video can be found at: https://youtu.be/HzrZO-0Vol4.
\end{abstract}

received

March 25, 2019 accepted after revision January 4, 2020 published online September 6, 2020
DOI https://doi.org/ $10.1055 / \mathrm{s}-0040-1705160$ ISSN 2193-6331.

\footnotetext{
(C) 2020. The Author(s).

This is an open access article published by Thieme under the terms of the Creative Commons Attribution-NonDerivative-NonCommercial-License, permitting copying and reproduction so long as the original work is given appropriate credit. Contents may not be used for commercial purposes, or adapted, remixed, transformed or built upon. (https://creativecommons.org/ licenses/by-nc-nd/4.0/) Georg Thieme Verlag KG, Rüdigerstraße 14, 70469 Stuttgart, Germany
} 


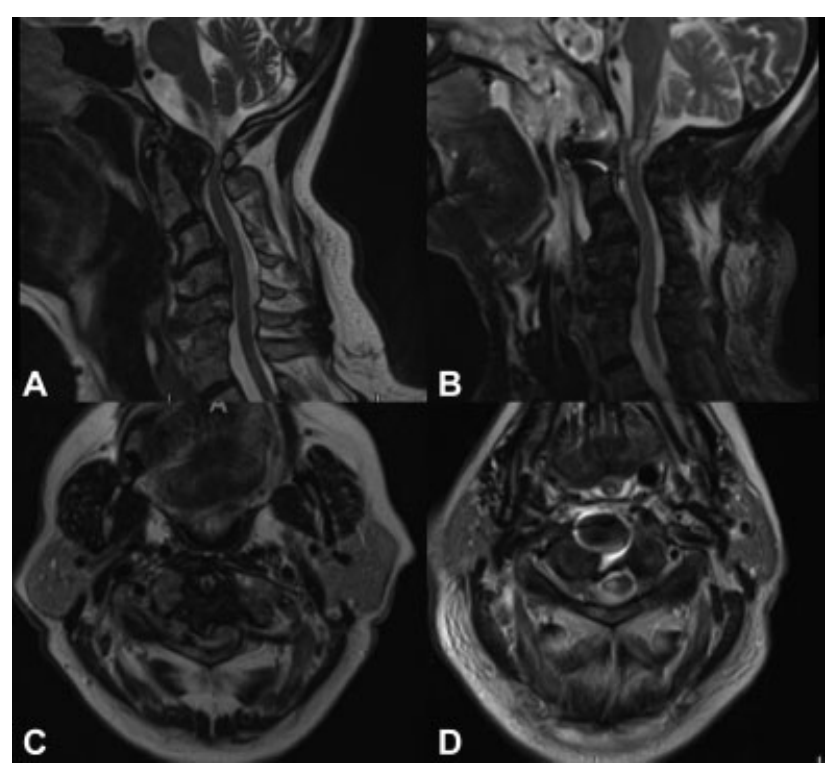

Fig. 1 Preoperative sagittal (A) and axial (C) MRI of the cervical spine demonstrating a large $C 1-C 2$ pannus severely compressing the spinal cord. Postoperative sagittal (B) and axial (D) MRI of the cervical spine demonstrating removal of the pannus and decompression of the spinal cord with evidence of residual myelomalacia. MRI, magnetic resonance imaging. note, it is important to determine the location of the parapharyngeal carotid arteries on preoperative scans since they can be retropharyngeal. A nasoseptal flap does not need to be raised at the beginning of the surgery, since the approach is below the sphenoid sinus. The lower clivus can be exposed without a sphenoidotomy. As the anterior arch of $\mathrm{C} 1$ is drilled, it can be difficult to visualize the transition to the dens. The goal of surgery is to remove inflammatory pannus until pulsations transmitted from the posterior fossa are noted. This can usually be accomplished without a cerebrospinal fluid leak. If there is a leak, a nasoseptal flap can be raised secondarily. A deep defect may need to be augmented with a fat graft. Excellent healing occurs by secondary intention over several weeks. The soft-tissue defect is above the level of Passavant's ridge and palatal dysfunction is rarely seen.

Carl H. Snyderman, MD University of Pittsburgh Pittsburgh, Pennsylvania

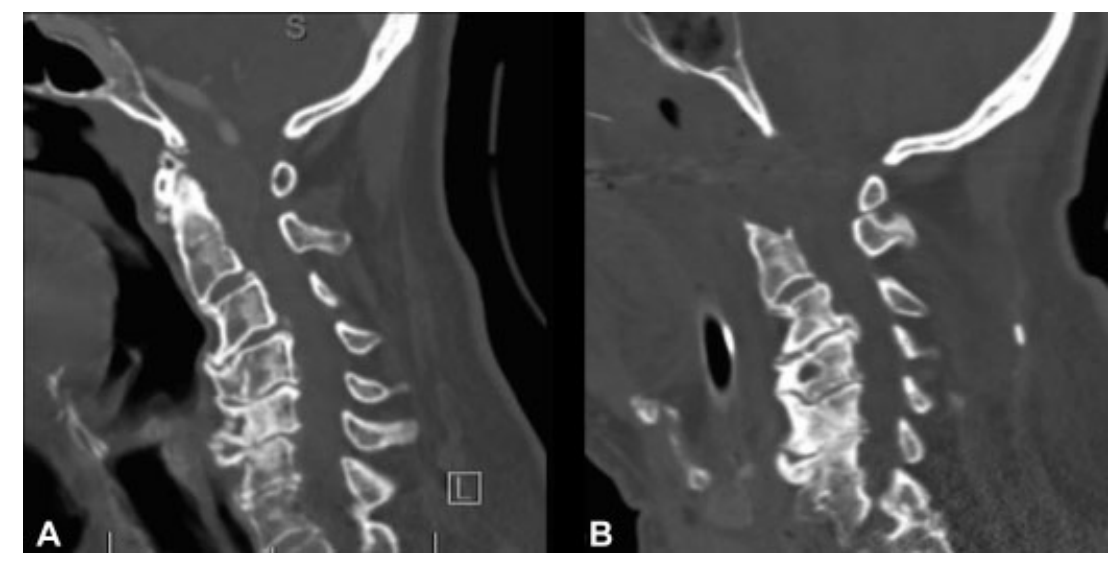

Fig. 2 (A) Preoperative and (B) postoperative sagittal CT of the cervical spine demonstrating resection of the anterior arch of C1 and the extent $\mathrm{C} 2$ dens resection. $\mathrm{CT}$, computed tomography.

\section{Comments}

This is a good demonstration of the basic technique for a transodontoid approach for $\mathrm{C} 1-\mathrm{C} 2$ pannus. As the authors 